\title{
Comparative characteristics of endovascular methods of stopping bleeding in placenta accrete
}

\begin{abstract}
Introduction: Currently, relatively rare complications of the early twentieth century, placenta accretes was transformed into perhaps the most common obstetric pathology requiring removal of the uterus. In the modern development of endovascular surgery becomes possible to significantly reduce the blood loss during childbirth and to preserve fertility.

Material and methods: The paper presents the experience of using endovascular methods to reduce blood loss. Depending on the kind of care for endovascular patients were divided into two groups. The first group $(\mathrm{n}=38)$ consisted of patients whose delivery is accompanied by temporary balloon occlusion of the common iliac arteries on both sides, and the second group $(\mathrm{n}=59)$ - the patient underwent embolization of the uterine arteries.

Results: Patients in both groups the use of modern technology - temporary balloon occlusion of the common iliac arteries and embolization of the uterine arteries in conjunction with hardware reinfusion of autologous eritrotsity-allowed to perform organsparing surgery all patients. The average intraoperative blood loss in patients of group I amounted to $1642 \pm 1146 \mathrm{ml}(27.5 \pm 22.0 \%$ BCC), $26.3 \%$ of patients recorded minimal blood loss $(700 \mathrm{ml})$. Complications of the postoperative period was observed in $2(6.25 \%)$ patients - in one case there was thrombosis of the common femoral artery requiring thrombectomy and execution in one patient, massive blood loss $(4000 \mathrm{ml})$, filled with large doses of fresh frozen plasma and donor red blood cell mass. In group II, the intraoperative blood loss averaged $1974 \pm 1445 \mathrm{ml}$ or $29.7 \pm 22.4 \%$ BCC, the volume of blood loss in one patient, demanded its transfer to the ventilation.
\end{abstract}

Conclusion: Temporary balloon occlusion of the common iliac arteries and uterine artery embolization are effective methods of reducing blood loss during delivery of patients with placenta accreta and uterine scar after cesarean section. With the availability of both techniques, preferably holding a temporary balloon occlusion, providing a significant reduction in blood loss volume.

It can be recommended for use in hospitals level III.

Keywords: placenta accreta, organ surgery, temporary balloon occlusion of the common iliac artery, embolisation, uterine artery

\section{Introduction}

Placenta growth (placenta accreta) is currently defined at a frequency of 1:1,200 genera, and according to several authors is the cause of extirpation of the uterus in $38-64 \%$ of observations. ${ }^{1-3}$ Placenta accreta remains the leading cause of massive obstetric haemorrhage due to the inability to contract the thinned lower uterine segment. Contributes to bleeding and gestational reconstruction of the vessels of the myometrium, which turn into a non-muscle hollow tube. The volume of blood loss reaches $3000-5000 \mathrm{ml}$, and in some patients reaches $16000 \mathrm{ml} .{ }^{4}$ For a long time hysterectomy was considered as an obligatory attribute in the delivery of patients with placenta accreta. ${ }^{5-10}$

Maximally reduce the arterial blood supply of the uterus can be by bandaging the main arteries of the pelvis or endovascularly. An invaluable contribution to the reduction of intraoperative blood loss is caused by endovascular interventions: transcatheter embolization of uterine arteries (EMA), often used when placenta is left in situ; Temporary balloon occlusion of internal iliac, common iliac arteries or aorta, used both for hysterectomy and metroplasty. Selective EMA is an alternative to surgical hemostasis, and with placenta accreta is successful in $50-87 \%$ of patients. ${ }^{11,12}$ Failures are usually associated with a well-developed network of collaterals, as well as a discrepancy between the size of the emboli and the diameter of the vessel. ${ }^{13}$
Volume 4 Issue 4 - 2018

\author{
Kurtser MA,' Grigoryan AM, ${ }^{2}$ Yu Breslav I,' \\ Evteev VB, ${ }^{2}$ Normantovich TO, ${ }^{3}$ Spiridonova \\ El, ${ }^{2}$ Platitsyin IV ${ }^{2}$ \\ 'NI Pirogov Russian National Research Medical University, \\ Russia \\ ${ }^{2}$ Clinical Hospital Lapino, Russia \\ ${ }^{3}$ Perinatal Medical Center, Russia
}

Correspondence: Grigoryan Ashot M, chief of the Department of endovascular methods of investigation and treatment, Clinical Hospital Lapino, I4308I, Moscow region, I-st Uspenskoe highway, Lapino, I I I, Russia, Tel +74955266060, Email Gashot@inbox.ru

Received: February 22, 2018 | Published: July 31, 2018
For the first time, temporary balloon occlusion of internal iliac arteries with abnormal attachment of the placenta was described in 1997. J Dubois et al. ${ }^{12}$ Since then, many publications have dealt with efficiencies up to $90 \%$ and complications associated with the installation of cylinders in a. iliaca interna. ${ }^{14-16}$ However, dissatisfaction with an insufficient decrease in the volume of blood loss contributed to a change in endovascular tactics. In 2005, an attempt was made to inflate balloon catheters in the common iliac arteries, which made the operating field practically "dry" 17 In the literature, information is extremely meager. In the available publications, temporary balloon occlusion a. iliaca communis was accompanied by extirpation of the uterus during cesarean section. ${ }^{18,19}$ Complications such as ischemic injury of the lower extremities due to thrombosis of the internal iliac or femoral artery in $15-16 \%$ of patients have been described. ${ }^{20}$ The lack of a single point of view on the preference for a particular type of endovascular aid in the growth of the placenta, a small number of articles devoted to the temporary occlusion of common iliac arteries on both sides, led to this study. ${ }^{21}$

\section{Hypothesis}

Temporary balloon occlusion of common iliac arteries on both sides in patients with placenta accreta and uterine scar after cesarean section is a more effective procedure compared with uterine artery 
embolization, allowing to significantly reduce the volume of blood loss, reduce postoperative and recovery periods.

\section{Materials and methods}

\section{Study design}

The criteria for inclusion of patients in the study were: 1) gestation period $\geq 28$ weeks; 2) pregnant women with a scar on the uterus after the previous operation of caesarean section; 3) placenta previa on the anterior wall of the uterus and in the region of the cicatrix; The study did not include patients with a gestation period of less than 28 weeks; Pregnant women with placenta previa without previous operation of cesarean section. All patients, depending on the type of endovascular intervention, were divided into two groups: group I-patients whose delivery was supplemented by temporary balloon occlusion of common iliac arteries on both sides $(n=38)$, group II-patients who before selective embolization performed selective embolization of the uterine arteries $(n=59)$. In both groups, blood loss, hemoglobin, erythrocyte, hematocrit before and 24 hours after surgery, postoperative bed-day, volume of autohemotransfusion, the volume of blood products required (fresh frozen plasma, donor erythrocyte mass) were estimated.

\section{Clinical characteristics of patients}

A retrospective examination of patients delivered at the Family Planning and Reproduction Center of the Moscow City Health Department, the Perinatal Medical Center in Moscow and the Lapino Clinical Hospital between 2009 and 2016 was carried out. All patients met the inclusion criteria. In all the observations, the diagnosis of placenta ingrowth was established by ultrasound examination, in which the following signs were observed: the presence of placental lacunae, the obliteration of the hypoechoic zone between the placenta and myometrium, the thinning of the myometrium less than $1 \mathrm{~mm}$, the absence of a clear boundary between the uterine wall and the bladder. In order to clarify the diagnosis, magnetic resonance imaging was carried out, the pathognomonic signs of placenta accreta were aneurysm of the inferior uterine segment, thinning of the myometrium adjacent to the placenta, various vascular placental lacunaes, the presence of pathological vessels that extend beyond the organ. Despite the comparability of sensitivity (80-90\%) and specificity (98\%) of both diagnostic methods, preference is given to a more economical method-ultrasound diagnostics. ${ }^{23}$

Depending on the type of endovascular intervention, all patients were divided into 2 groups. The first group consisted of 38 patients, whose delivery was supplemented by temporary balloon occlusion of the common iliac arteries on both sides, and the second group consisted of 59 patients who underwent selective uterine artery embolization prior to removal of the placenta. Both groups were statistically comparable in age, weight, number of pregnancies, labor and scars on the uterus, gestation period, uterine aneurysm area (Table $1)$.

In patients of the first group, varicose veins were prominent among somatic diseases - in 9 (23.6\%), chronic pyelonephritis-in $5(13.1 \%)$, hereditary thrombophilia-in $1(2.6 \%)$. Of the gynecological diseases, the subserous uterine fibroids were observed in $2(5.2 \%)$ women, paraovarian cyst in $1(2.6 \%)$. All pregnancies were spontaneous, of them $3(7.9 \%)$ twins. All patients had a caesarean section in their history. The scar after one operation was in 17 (44.7\%), after two operations-in $14(36.8 \%)$, after three-in 5 (13.2\%), after four in $2(5.3 \%)$. Artificial or spontaneous abortions in the history had $19(50.0 \%)$ patients. In $1(1.6 \%)$ patients of group II, autoimmune thyroiditis took place. Among gynecological diseases, uterine fibroids were observed in $2(3.3 \%)$ patients. All pregnancies were spontaneous. The scar after one operation was in $32(54.2 \%)$, after two operations in $22(37.3 \%)$, after three - in $5(8.5 \%)$ of the examined. The gestation period at the time of delivery in patients of groups I and II is presented in Table 2.

Table I Comparative characteristics of patients in groups I and II

\begin{tabular}{lllll}
\hline № & Parameter & I group & II group & P \\
\hline I & Age (years) & $33.6 \pm 4.2$ & $33.7 \pm 4.4$ & 0.05 \\
2 & Weight $(\mathrm{kg})$ & $74.3 \pm 9.8$ & $76.5 \pm 11.5$ & 0.05 \\
3 & The number of pregnancies & $4.4 \pm 2.2$ & $4.1 \pm 1.9$ & 0.05 \\
4 & The number of births & $3.1 \pm 1.7$ & $2.7 \pm 1.0$ & 0.05 \\
5 & Number of scars on the uterus & $1.7 \pm 0.8$ & $1.5 \pm 0.6$ & 0.05 \\
6 & The gestational age (weeks) & $35.5 \pm 2.5$ & $36.8 \pm 1.8$ & 0.05 \\
7 & Area of uterine aneurysm $\left(\mathrm{cm}^{2}\right)$ & $274.4 \pm 173.8$ & $196.1 \pm 106.2$ & 0.05 \\
\hline
\end{tabular}

Table 2 Duration of gestation of patients with placenta accreta

\begin{tabular}{llllll}
\hline & $\begin{array}{l}\text { Duration of } \\
\text { gestation (weeks) }\end{array}$ & I group & $\%$ & II group & $\%$ \\
\hline I & $<34$ week & 12 & 31.6 & 4 & 6.8 \\
2 & $35-38$ & 23 & 60.5 & 49 & 83.1 \\
3 & $>38$ week & 3 & 7.9 & 6 & 10.1 \\
& Total & 38 & 100 & 59 & 100 \\
\hline
\end{tabular}


The majority of patients of groups I and II - 23 $(60.5 \%)$ and $49(83.1 \%)$ were delivered at $35-38$ weeks. In $8(21.1 \%)$ women of group I, according to the results of MRI, it was impossible to exclude the involvement of the posterior wall of the bladder, which was intimately soldered to the thin lower segment of the uterus. In group II of such patients there were 4 (6.8\%). Technique of endovascular operations. In the case of temporary balloon occlusion of the common iliac arteries, the endovascular stage is performed after the extraction of the child. According to the method of Seldinger, the puncture of the common femoral artery is performed from one side and the other, after which introducers are installed. The diameter of the introducer is chosen according to the diameter of the balloon catheter. In the abdominal aorta, diagnostic J-conductors of 0.035 "are placed and installed. Conductors conduct and install in the projection of the bifurcation of the abdominal aorta with the transition to the common iliac artery balloon-catheters Opta (Cordis), Admiral (Invatec). The diameter of the balloon catheter is selected in such a way that it does not exceed more than $1 / 3$ the diameter of the total femoral artery, determined from the data of the duplex scan at early gestation. After positioning the balloon catheter, the latter is inflated with a syringemanometer at a pressure of 6-8 atm. Through the lateral port of one of the inflated cylinders the conductor is temporarily removed and the contrast medium Omnipak or Nycomed is injected. The absence of a contrast agent distal to the balloon catheter indicates a reliable overlap of the artery lumen. After being convinced that the blood flow distal to the balloon catheter is absent, the conductor is again injected into the lateral port and installed in the abdominal aorta. Balloon catheters are fixed to the skin of the thigh to prevent their dislocation during manipulations to remove the placenta. During the midwifery phase with a 20-minute interval, the cylinders are alternately deflated for $30-40$ seconds to restore blood flow to the common iliac arteries in the pelvic organs and lower limbs. After completion of the obstetric phase, balloon catheters are blown off, haemostasis is removed and performed.

Embolization of the uterine arteries also begins with a puncture according to the Seldinger method of the common femoral artery on the one hand. After the introduction of the introducer, selective catheterization of uterine arteries is performed sequentially from one side and the other side by a catheter such as Cobra (Cordis) or AUB (Terumo). After catheterization of the uterine arteries, particles of PVA (Cook) 510-700 mk are inserted into each of them. Control angiography demonstrates the absence of blood flow through the uterine arteries, followed by the obstetric phase. After extraction of the placenta, the introducer is removed and hemostasis is performed.

\section{Statistics}

Statistical processing of data was carried out using the SPSS for Windows Version 19.0 application package (IBM Corp.). The data are represented by the median and interquartile latitude - Me (P25; P75). The normality test was carried out using the Kolmogorov-Smirnov test. To evaluate the results of treatment in each group, the Wilcoxon sign criterion was used, to compare data between subgroups, the Mann-Whitney U test. Statistically significant differences were considered for $\mathrm{p}<0.05 .{ }^{24}$

\section{Results of the study}

When performing the delivery with endovascularsupport, all patients managed to perform an organ-preserving operation. Metroplasty, consisting in excision of altered tissue of the uterus with a pathologically attached placenta, was performed in all puerperas. In 8 (21.1\%), a resection of the bladder was required because of the impossibility of its separation among the patients of group I and in $4(6.8 \%)$ in group II. Delivery was routinely performed in 29 (76.3\%) women of the I group, while in 9 (23.4\%), it was performed according to emergency indications caused by bleeding from the genital tract. The bottom incision on the uterus during cesarean section was performed in $37(97.3 \%)$ patients, corporal over the placenta-in 1 $(2.7 \%)$.

All children were born in a satisfactory condition. The body weight ranged from 1200 to 3690 grams, an average of $2581 \pm 562$ grams. Fifteen (37.5\%) of newborns were weighing from 1200 to 2500 grams, and $25(62.5 \%)$ with a body weight of more than 2500 grams $(2530$ to 3690).Among the patients of Group II, 58 (98.3\%) were surgically operated, in an emergency $1(1.7 \%)$ maternity wards. All patients of group II underwent a bottom incision on the uterus. As in Group I, all children of Group II patients were born in a satisfactory condition. The body weight at birth was on average $3143 \pm 536$ grams, ranging from 1300 to 4690 grams. With a body weight of up to 2500 grams. 8 (13.6\%) children were born, and over 2500gr. -51 (86.4\%) children. In the first group of patients, after the extraction of the fetus for the purpose of hemostasis, temporary balloon occlusion of the common iliac arteries on both sides was performed before metaplasty, and in the second group for this purpose embolization of the uterine arteries was performed on both sides. The effectiveness of endovascular support methods was assessed by: the level of blood loss (volume and percentage of circulating blood volume), changes in red blood before surgery and in the postoperative period (hemoglobin, erythrocyte, hematocrit), reinfusion volume of autologous eritrovissivities and infusion therapy (NWP use and donor erythrocytes). The volume and magnitude of blood loss for patients of both groups is presented in Table 3. For group 1 patients, the blood loss value ranged from 400 to $4800 \mathrm{ml}$, or $27.5 \pm 22.0 \% \mathrm{BCC}$, averaging $1642 \pm 1146 \mathrm{ml}$. Have the majority of patients-29 (76.3\%)-the blood loss value did not exceed $2000 \mathrm{ml}$ (18 patients with blood loss to $1000 \mathrm{ml}$ and 11 from 1000 to $2000 \mathrm{ml})$.

In group II, the blood loss volume averaged $1974 \pm 1445 \mathrm{ml}$, or $29.7 \pm 22.4 \%$ BCC, varying from 400 to $6000 \mathrm{ml}$. In this group, the number of patients with blood loss up to $2000 \mathrm{ml}$ was 43 (72.9\%), while, in contrast to group I, patients with blood loss from 1000 to $2000 \mathrm{ml}$ prevailed $(25.4 \%)$, while with blood loss to $1000 \mathrm{ml}$ was $18(30.5 \%)$ of the patients. With the aim of replenishment of blood loss, hardware reinfusion of autoerithrocytes, transfusion of FFP and donor erythrocytes was carried out. In group I, the hardware reinfusion of the autologous erythrocyte suspension was performed in $37(97.4 \%)$ of the puerperas. Among the patients who underwent hardware reinfusion, in 29 (78.4\%) cases it was performed using one Cell Saver device, and in 8 cases by means of a combination of two devices - Cell Saver and CATS. An average of $1754 \pm 1660 \mathrm{ml}$ of blood was collected, reinfusion - 804 $\pm 643 \mathrm{ml} .26(68.4 \%)$ patients needed transfusion therapy, $19(73.1 \%)$ required transfusion of FFP in volume $1474 \pm 556 \mathrm{ml}$, and in $7(26.9 \%)$ - erythrocyte mass in the volume of $1082 \pm 474 \mathrm{ml}$. Among the patients of group II, the proportion of those who needed the hardware reinfusion of the autologous erythrocyte suspension was $91.5 \%$ (54 patients). All women used only one device - Cell Saver, through which an average of $1900 \pm 1304 \mathrm{ml}$ was collected, and the reinfusion volume was $1057 \pm 820 \mathrm{ml} .39(66.1 \%)$ patients needed transfusion of blood components: 33 (84.6\%) cases, FFP transfusion in the volume averaged $1531 \pm 846 \mathrm{ml}, 6(15.4 \%)$ donor red blood cells in the volume of $600 \pm 176 \mathrm{ml}$. 
Table 3 The volume of blood loss in patients with placenta accreta

\begin{tabular}{|c|c|c|c|c|c|c|c|}
\hline & \multicolumn{7}{|c|}{2016 Completed } \\
\hline & \multicolumn{6}{|c|}{ The volume of blood loss $(\mathrm{ml})$} & \multirow[t]{2}{*}{ Total } \\
\hline & $<1000$ & $100 \mid-2000$ & $200 I-3000$ & $300 I-4000$ & $4200-4800$ & $>4801$ & \\
\hline I group (number of pts) & I 8 (47.4\%) & II (28.9\%) & $4(10.5 \%)$ & $3(7.9 \%)$ & $2(5.3 \%)$ & --- & $38(100 \%)$ \\
\hline II group (number of pts) & $18(30.5 \%)$ & 25 (30.5\%) & 7 (II.8\%) & $2(3.4 \%)$ & $2(3.4 \%)$ & $5(3.4 \%)$ & $59(100 \%)$ \\
\hline
\end{tabular}

The change in red blood indices (hemoglobin, erythrocytes and hematocrit) for patients of both groups before and after the operation is shown in Figure 1. The hemoglobin level for patients of the I group at the preoperative period ranged from 76 to $130 \mathrm{~g} / 1$, averaging 104.5 (95.25; 115), and for patients of Group II $112(107 ; 118)$ (it ranged from 53 to $141 \mathrm{~g} / 1)$. In the postoperative period, this indicator was 91 $(80.25,101.25)$ for patients of Group I and $96(87.5,105.5)$ for patients of Group II, respectively. The erythrocyte index was $3.4(3.29,3.7)$ in the preoperative period in the preoperative period, ranging from 2.3
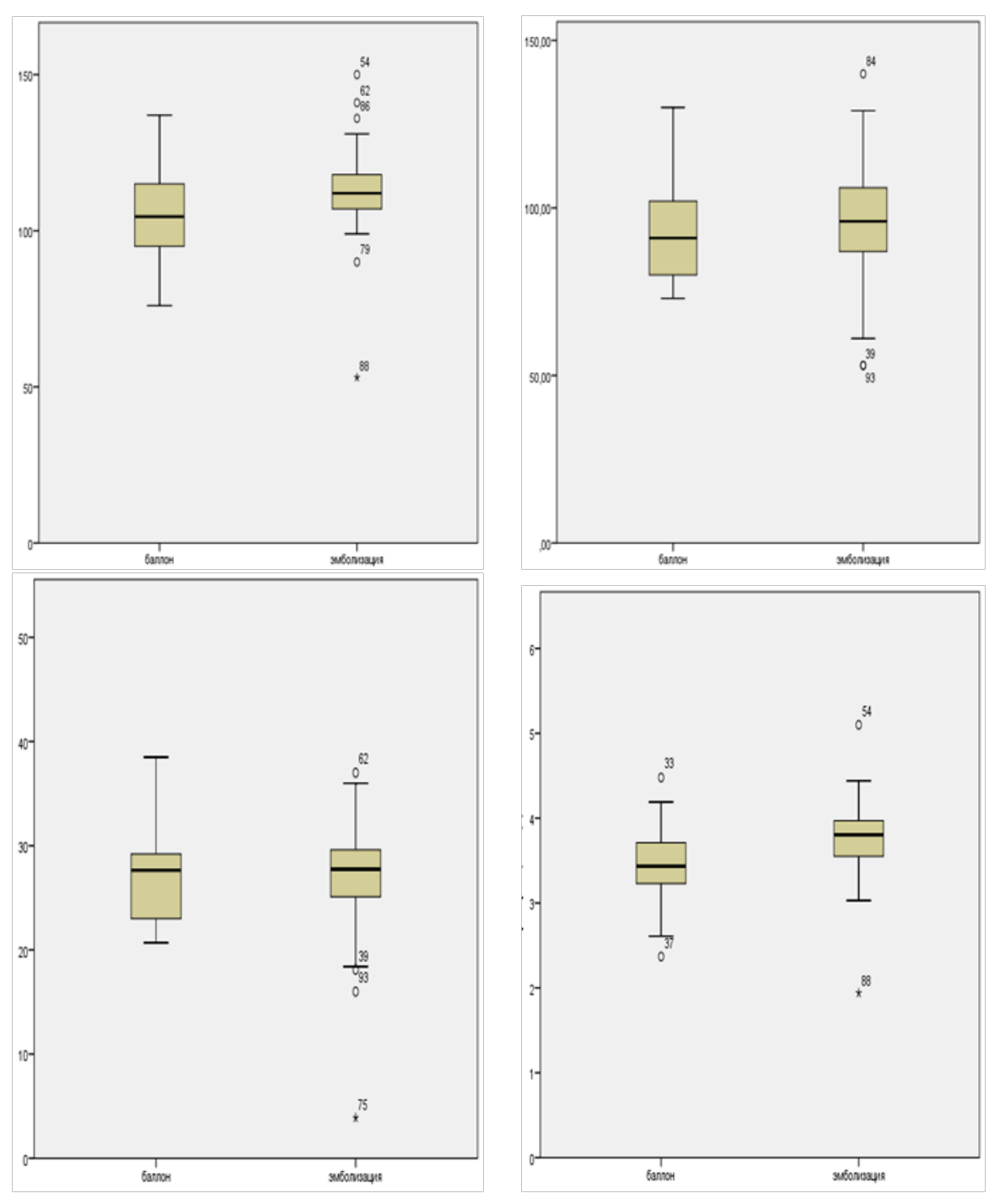

to $4.4 \times 10 \times 12$, and for patients of Group II $3.8(3.5,4.01)$, ranging from 1.9 to $4.4 \times 10 \times 12$. In the postoperative period, the level of erythrocytes for group I was $2.9(2.6,3.4)$, and for group II - $3.2(2.7$, 3.74). The level of hematocrit in the patients of the I group was 30.8 $(27.5,34.1) \%$ (varied from 21 to $42 \%$ ), while in the patients of the II group it was $32.7(31.1,34.9) \%$, varying from 18.5 to $44.6 \%)$. In the postoperative period, the hematocrit was $27.65(23.1,29.1)$ and 27.75 $(25.13,29.6)$, respectively, for patients of groups I and II.
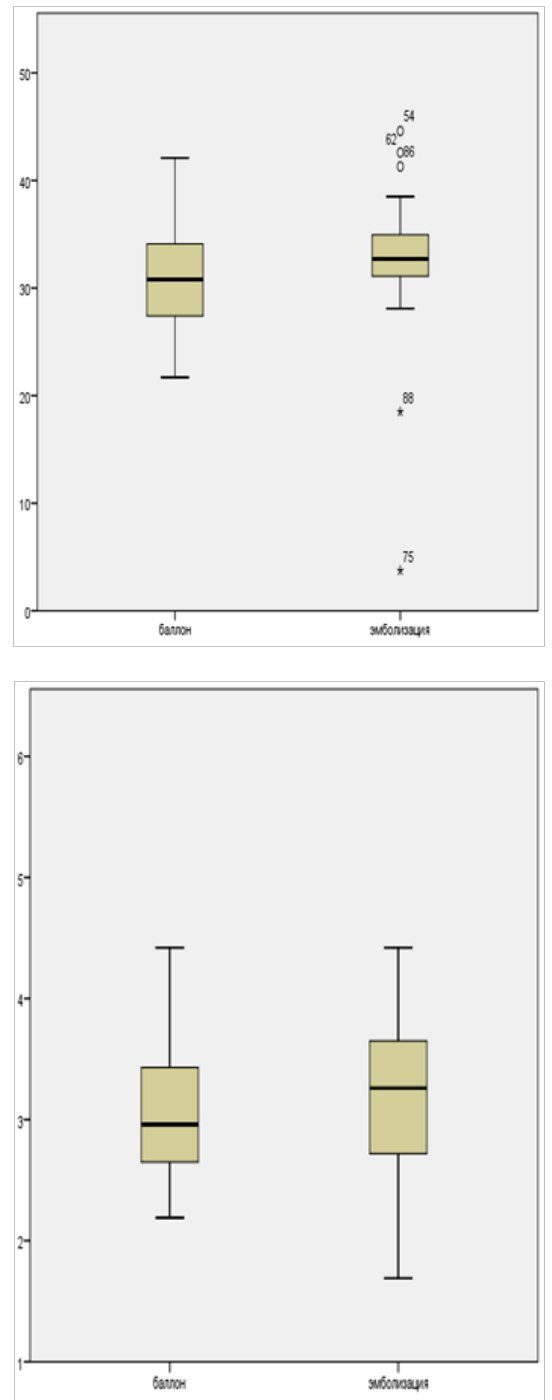

Figure I Change in hemoglobin (a, b), hematocrit (c, d) and erythrocyte (e, e) in both groups before and after the intervention. 
The duration of surgical intervention for Group I patients was 161.5 [128.7;200], and for Group II-175 [145;218.7] min (Figure 2). The duration of the postoperative period was comparable in patients of groups I and II and was 9 [7;11] days for patients of Group I and 9 $[8 ; 11]$ days for patients of Group II, respectively (Figure 3 ).

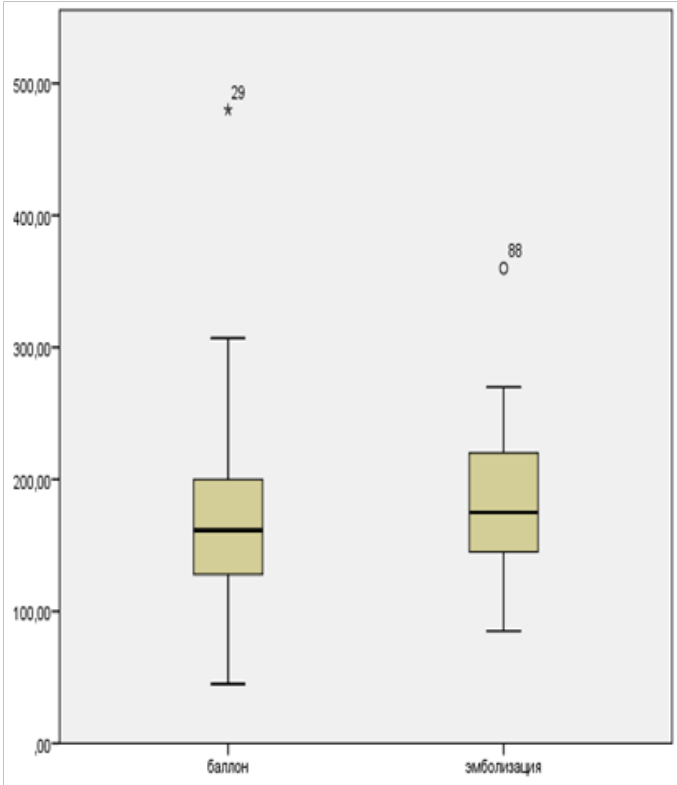

Figure 2 Duration of surgical intervention in patients with placenta accreta, depending on the type of endovascular care.

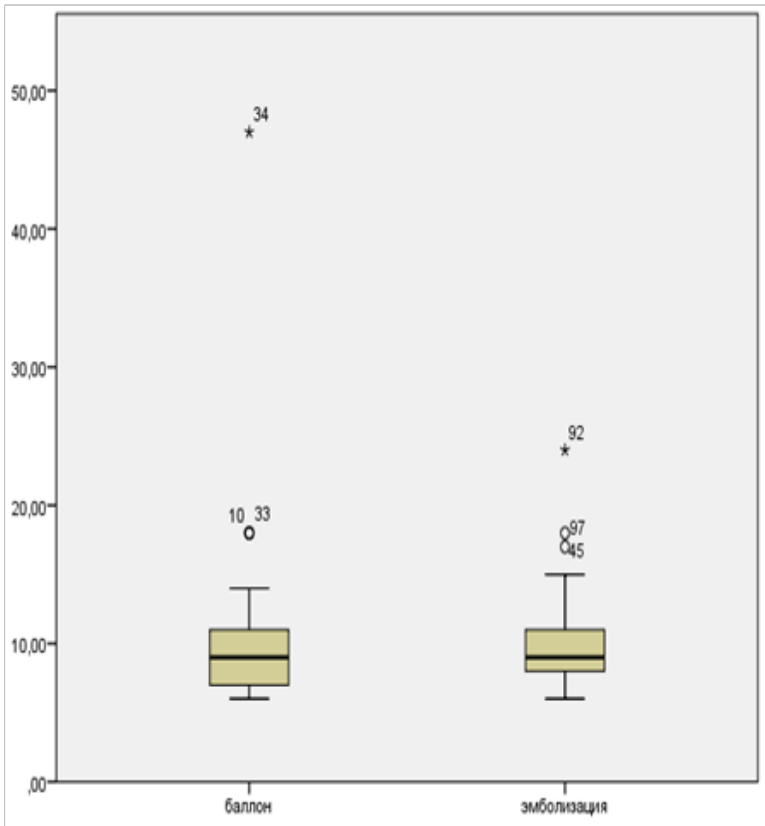

Figure 3 Length of stay of patients with placenta accreta in a hospital depending on the type of endovascular care.

Complications of the nearest postoperative period were observed in $5(13.2 \%)$ patients of group I. Among complications of the postpartum period associated with placenta accrete, it should be noted: uterine bleeding in the early postpartum period in one patient and on the 7 th day in the second patient, which required the embolization of uterine arteries to both puerperas; intraperitoneal bleeding of $1000 \mathrm{ml}$ volume 10 hours after the operation, in connection with which relaparotomy and additional hemostatic sutures were performed; tamponade of the bladder with a clot, which was diagnosed by ultrasound on the 5 th day, was eliminated during urethrocystoscopy by coagulation of the bleeding vessel; thrombosis of the femoral artery in the early postoperative period in connection with the rupture of the balloon at the next injection of the mixture by a syringe-manometer, was eliminated by thrombectomy. It should be noted that among the five complications of the postpartum period, only one-thrombosis of the common femoral artery was directly related to the endovascular support provided, in the remaining cases the developed complications are related to the technical features of the operation being performed.

The results show the possibility and effectiveness of the application of temporary balloon occlusion of common iliac arteries in patients with scar on the uterus after a cesarean section and placenta acreta. The duration of surgical intervention in the puerperas who underwent a temporary balloon occlusion of the general iliac arteries was significantly lower than in patients whose delivery was supplemented by uterine artery embolization - 161.5 [128.7; 200], and $175[145 ; 218.7] \mathrm{min}$ respectively. There was a slight predominance in the reduction of red blood for patients of Group II. Thus, the level of erythrocytes in patients of group I decreased 1.17 times from 3.4 $(3.29,3.7)$ vs $2.9(2.6,3.4)$, while in patients of group II it was 1.18 times $(3.8(3,5,4.01)$ vs $3.2(2.7,3.74)$ The level of hemoglobin $104.5(95.25,115)$ vs $91(80.25,101.25)$ (a decrease of 1.14 times for patients of group I) and $112(107 ; 118)$ vs $96(87.5,105.5)$, a decrease of 1.16 times for group 2. In turn, the hematocrit in group I decreased from $30.8(27.5,34.1)$ vs $27.6523,1,29,1)$ (decrease by 1.1 times), and in group II $32.7(31.1,34.9)$ vs $27.75(25.13,29.6)-1.2$ times Also among the patients I group was significantly lower than the blood loss amount of $1642 \pm 1146 \mathrm{ml}$ (or $27.5 \pm 22.0 \%$ bcc) versus $1974 \pm 1445 \mathrm{ml}$ (or $29.7 \pm 22.4 \%$ OC.

\section{Conclusion}

However, it should be noted that this study is the first study in the country in which the experience of just one clinic is used. For a final understanding of the advantages of this or that method of preventing massive obstetric hemorrhage through endovascular methods, a multicenter, randomized trial is needed.

\section{Acknowledgments}

None.

\section{Conflicts of interest}

The author declares there are no conflicts of interest.

\section{References}

1. Chantraine F, Braun T, Gonser M, et al. Prenatal diagnosis of abnormally invasive placenta reduces maternal peripartum hemorrhage and morbidity. Acta Obstet Gynecol Scand. 2013;92(4):439-444.

2. Timor-Tritsch IE, Monteagudo A, Cali G, et al. Cesarean scar pregnancy and early placenta accreta share common histology. Ultrasound Obstet Gynecol. 2014;43(4):383-395.

3. Knight M. Peripartum hysterectomy in the UK: management and outcomes of the associated haemorrhage. BJOG. 2007;114(11):13801387. 
4. Shrivastava V, Nageotte M, Major C, et al. Case-control comparison of cesarean hysterectomy with and without prophylactic placement of intravascular balloon catheters for placenta accreta. Am J Obstet Gynecol. 2007;197(4):402.

5. ACOG Committee Opinion. Placenta accreta. American College of Obstetricians and Gynaecologists. 2012;120(1):207-211.

6. Broekman EA, Versteeg H, Vos LD, et al. Temporary balloon occlusion of the internal iliac arteries to prevent massive hemorrhage during cesarean delivery among patients with placenta previa. Int J Gynaecol Obstet. 2015;128(2):118-121.

7. Minas V, Gul N, Shaw E, et al. Prophylactic balloon occlusion of the common iliac arteries for the management of suspected placenta accreta/ percreta: conclusions from a short case series. Arch Gynecol Obstet. 2015;291(2):461-465.

8. Silver RM, Barbour KD. Placenta accreta spectrum: accreta, increta, and percreta. Obstet Gynecol Clin North Am. 2015;42(2):381-402.

9. Palacios Jaraquemada JM, Pesaresi M, Nassif JC, et al. Anterior placenta percreta: surgical approach, hemostasis and uterine repair. Acta Obstet. Gynecol Scand. 2004;83(8):738-744.

10. D'Souza DL, Kingdom JC, Amsalem H, et al. Conservative management of invasive placenta using combined prophylactic internal iliac artery ballon occlusion and immediate postoperative uterine artery embolization. Can Assoc Radiol J. 2015;66(2):179-184.

11. Duan XH, Wang YL, Han XW, et al. Caesarean section combined with temporary aortic balloon occlusion followed by uterine artery embolization for the management of placenta accrerta. Clin Radiol. 2015;70(9):932-937.

12. Dubois J, Garel L, Grignon A, et al. Placenta percreta: balloon occlusion and embolization of the internal iliac arteries to reduce intraoperative blood losses. Am J Obstet Gynecol. 1997;176(3):723-726.

13. Eller AG, Bennett MA, Sharshiner M, et al. Maternal morbidity in cases of placenta accreta by a multidisciplinary care team compared with standard obstetric care. Obstet Gynecol. 2011;117(2):331-337.

14. Dilauro MD, Dason S, Athreya S. Prophylactic ballon occlusion of internal iliac arteries in women with placenta accreta: literature review and analysis. Clin Radiol. 2012;67(6):515-520.
15. Gagnon J, Boucher L, Kaufman I, et al. Iliac artery rupture related to balloon insertion for placenta accrete causing maternal hemorrhage and neonatal compromise. Can J Anesth. 2013;60(12):1212-1217.

16. Teixidor Viñas M, Chandraharan E, Moneta MV et al. The role of interventional radiology in reducing haemorrhage and hysterectomy following caesarean section for morbidly adherent placenta. Clin Radiol. 2014;69(8):e345-351.

17. Shih JC, Liu KL, Shyu MK. Temporary balloon occlusion of the common iliac artery: new approach to bleeding control during cesarean hysterectomy for placenta percreta. Am J Obstet Gynecol. 2005;193(5):1756-1758.

18. Matsubara S, Nonaka $\mathrm{H}$, Kobayashi $\mathrm{M}$, et al. Intrauterine balloon occlusion during caesarean hysterectomy for placenta previa accreta: the internal or common iliac artery? Acta Obstet Gynecol Scand. 2014;93(1):122-123.

19. Hishikawa K, Koshiyama M, Ueda M, et al. Exchange of intraoperative balloon occlusion of the internal iliac artery for the common iliac artery during cesarean hysterectomy in a patient with placenta percreta. Am J Case Rep. 2013;14:409-411.

20. Chou MM, Kung HF, Hwang JI, et al. Temporary prophylactic intravascular balloon occlusion of the common iliac arteries before cesarean hysterectomy for controlling operative blood loss in abnormal placentation. Taiwan J Obstet Gynecol. 2015;54(5):493-498.

21. Kurtser MA, Breslav I Yu, Grigoryan AM, et al. Experience with temporary balloon occlusion of the common iliac arteries in patients with placenta increta during organsparing operations. Akusherstvo $i$ Ginekologiya/Obstetrics and Gynecology. 2013;(7):80-84.

22. Kurtser MA, Breslav I Yu, Latyshevich OA, et al. Experience of preserving surgery for placenta accreta in a patient with twins pregnancy. Voprosyi ginekologii, akusherstva i perinatologii. 2015;14(4):75-78.

23. Latyshevich OA, Kurtser MA, Savelyeva GM, et al. Antenatal diagnosis of placenta accreta in women with caesarean section history. Voprosyi ginekologii, akusherstva i perinatologii. 2013;12(6):36-41.

24. Lang TA. How to describe statistics in medicine. Annotated guidelines for authors, editors and reviewers. Practical medicine. 2011. 480 p. 